\section{IIUPAC Awards in Analytical Chemistry-Call for nominations}

\section{he Analytical Chemistry Division of IUPAC has established two awards, including:}

- The Emerging Innovator Award in Analytical Chemistry-an award to recognize outstanding work undertaken by an emerging analytical scientist that corresponds to the aims of the Analytical Chemistry Division.

- $\quad$ The IUPAC Analytical Chemistry Medal-an award to recognize a significant lifetime contribution to the aims of the Analytical Chemistry Division.

The awards are open worldwide to researchers working in the field of analytical chemistry. The Emerging Innovator Award is for researchers who are at an early stage of their independent career, as measured by the completion of a PhD within the last ten years. Appropriate consideration will be given to those who have taken a career break or followed a different study path. Nominations must be based on published works in the field of analytical chemistry. The Analytical Chemistry Medal is for researchers who have a substantial record of achievements demonstrated by the number and quality of their publications, by being actively involved in international partnerships as well as by their commitment in the training of the next generation of analytical chemists.

The Award will be presented every two years during the IUPAC General Assembly/ World Chemistry Congress. The awardees will be invited to the meeting of the Analytical Chemistry Division to receive their award and to present a lecture.

Complete applications must be received via the submission form no later than 31 January 2021.

Medal The Prize is managed by the Analytical Chemistry Division (ACD, Division V) of IUPAC. For information, please contact IUPAC by email at $<$ ACD-award@iupac.org>.

https://iupac.org/iupac-awards-in-analytical-chemistry-call-for-nominations/

\section{UMRS Survey on the Evolution of Scientific Publishing}

n 2018, the International Union of Materials Research Societies (IUMRS) initiated a survey with the intension of collecting opinions and some related demographics which, when aggregated, may provide a fresh perspective on the scientific publishing enterprise from viewpoint of the very people who are most closely affected by it.

The results represent an attempt to portray the current attitudes and actions connected with the broad topic of scientific publishing, as perceived by many different communities served by, or dependent upon, the publication process. The report, in its full 57 pages, includes the detailed analysis of responses from various types of respondent. Some broad conclusions are presented, while common themes repeatedly arise. They reflect a general concern about several major aspects of the social and professional environment in which we work. These include:

- Widespread unhappiness with the linkage between personal or professional success and both the number of publications produced and the obligation to publish in journals with high impact factor.

- Concern about the proliferation of new narrowly focused journals designed for easy acceptance of low-quality manuscripts.

- An ongoing concern about the fairness and objectivity of the peer-review system.

- A concern about the wide range of fees charged for open access publication as well as about nonuniform subscription costs paid by various subscribers-ranging from university libraries to individual projects and funding agencies.

The data analysis and full text report (PDF 57 pages) is available online at https://tinyurl.com/SurveyAnalysis-and-Report.

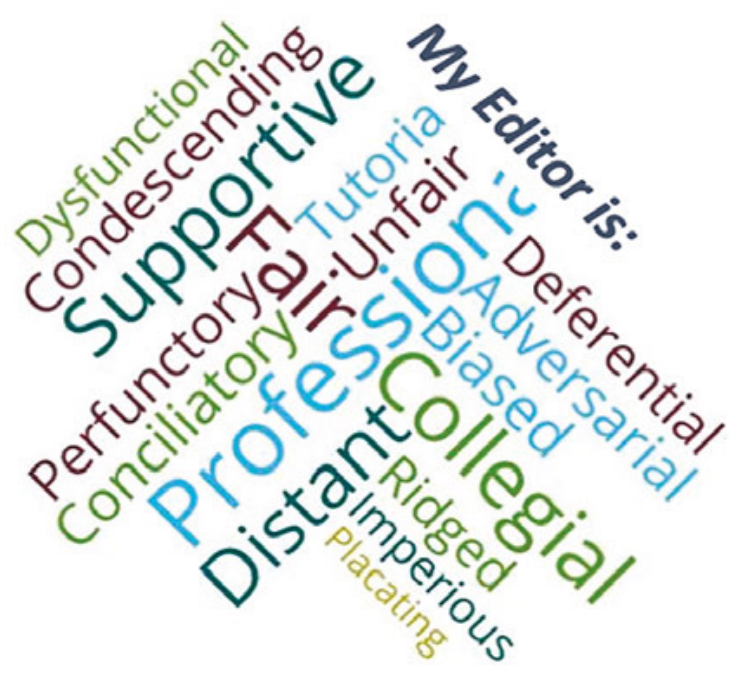

Logarithmic word cloud of researcher-editor relationship descriptors (see report page 14). 